\title{
Dehydratase mediated 1-propanol production in metabolically engineered Escherichia coli
}

Rachit Jain and Yajun Yan ${ }^{*}$

\begin{abstract}
Background: With the increasing consumption of fossil fuels, the question of meeting the global energy demand is of great importance in the near future. As an effective solution, production of higher alcohols from renewable sources by microorganisms has been proposed to address both energy crisis and environmental concerns. Higher alcohols contain more than two carbon atoms and have better physiochemical properties than ethanol as fuel substitutes.

Results: We designed a novel 1-propanol metabolic pathway by expanding the well-known 1,2-propanediol pathway with two more enzymatic steps catalyzed by a 1,2-propanediol dehydratase and an alcohol dehydrogenase. In order to engineer the pathway into E. coli, we evaluated the activities of eight different methylglyoxal synthases which play crucial roles in shunting carbon flux from glycolysis towards 1-propanol biosynthesis, as well as two secondary alcohol dehydrogenases of different origins that reduce both methylglyoxal and hydroxyacetone. It is evident from our results that the most active enzymes are the methylglyoxal synthase from Bacillus subtilis and the secondary alcohol dehydrogenase from Klebsiella pneumoniae, encoded by mgs $A$ and budC respectively. With the expression of these two genes and the E. coli ydjG encoding methylglyoxal reductase, we achieved the production of 1,2-propanediol at $0.8 \mathrm{~g} / \mathrm{L}$ in shake flask experiments. We then characterized the catalytic efficiency of three different diol dehydratases on 1,2-propanediol and identified the optimal one as the 1,2-propanediol dehydratase from Klebsiella oxytoca, encoded by the operon ppdABC. Co-expressing this enzyme with the above 1,2-propanediol pathway in wild type E. coli resulted in the production of 1-propanol at a titer of $0.25 \mathrm{~g} / \mathrm{L}$.

Conclusions: We have successfully established a new pathway for 1-propanol production by shunting the carbon flux from glycolysis. To our knowledge, it is the first time that this pathway has been utilized to produce 1propanol in E. coli. The work presented here forms a basis for further improvement in production. We speculate that dragging more carbon flux towards methylglyoxal by manipulating glycolytic pathway and eliminating competing pathways such as lactate generation can further enhance the production of 1-propanol.
\end{abstract}

\section{Background}

The excessive utilization of petroleum plays a major role in the release of the green house gas-carbon dioxide contributing to global warming. Renewable energy sources provide a wide platform of resources to address the problem of increasing energy demand. The manufacture of biofuels such as higher chain alcohols from renewable sources provides an alternative energy source which possesses the advantage of having desirable fuel properties and uncomplicated transportability [1-4]. The synthesis of

\footnotetext{
* Correspondence: yajunyan@uga.edu

Biochemical Engineering Program, Faculty of Engineering, University of Georgia, Athens, GA 30602 USA
}

various higher chain alcohols has been achieved by constructing biosynthetic pathways in E. coli and other microorganisms [1-7]. Here, we describe the design of a new pathway for 1-propanol synthesis and its validation in E. coli.

In petrochemical industry, 1-propanol is produced from ethene by a reaction with carbon monoxide and hydrogen to give propionaldehyde, which is then hydrogenated [8]. 1 -propanol is also produced as a by-product when potatoes or grains are fermented during the commercial manufacture of ethanol $[8,9]$. The general use of 1-propanol is in the manufacture of drugs and cosmetics such as lotions,
C Biomed Central

다 2011 Jain and Yan; licensee BioMed Central Ltd. This is an Open Access article distributed under the terms of the Creative Commons Attribution License (http://creativecommons.org/licenses/by/2.0), which permits unrestricted use, distribution, and reproduction in any medium, provided the original work is properly cited. 
soaps, and nail polishes. It also finds applications in the manufacture of flexographic printing ink and textiles $[8,9]$.

Recently, the use of 1-propanol as a potential fuel substitute to petroleum has promoted the interest in its production via biological approaches. In 2008, Atsumi et al. and Shen et al. reported the production of 1-propanol from glucose by metabolic engineering of $E$. coli. Their work relied on the keto-acid pathway in $E$. coli with 2-ketobutyrate as a key intermediate [1,7]. The 2-ketobutyrate was converted to 1-propanol by the action of a keto acid decarboxylase and an alcohol dehydrogenase. Wild type E. coli carrying this pathway was able to produce around $0.15 \mathrm{~g} / \mathrm{L}$ of 1-propanol. With the elimination of the genes $\operatorname{met} A$, $t d h, i l v B, i l v l$ and $a d h E$ encoding the enzymes $o$-succinyltransferase, threonine dehydrogenase, acetohydroxy acid synthase and alcohol dehydrogenase respectively, the production of 1-propanol achieved was $1 \mathrm{~g} / \mathrm{L}$. Atsumi et al. [2] reported higher levels of 1-propanol production in $E$. coli using $\operatorname{cim} A$ encoding a citramalate synthase from Methanoccus jannaschii. They established a direct route for the conversion of pyruvate to 2-ketobutyrate. With the utilization of citramalate pathway and incorporating an evolutionary strategy based on growth they were able to overcome feedback inhibition by isoleucine. Using wild type $\operatorname{cim} A$ they achieved $0.3 \mathrm{~g} / \mathrm{L}$ of 1 -propanol production. With the development of $\operatorname{cim} A$ variants, the production of 1-propanol was 9 times higher compared to the wild type $\operatorname{cim} A$.

We developed a new approach for the biosynthesis of 1propanol by extending the well-known 1,2-propanediol pathway. As the pathway scheme shown in Figure 1, the intermediate of glycolysis dihydroxyacetone phosphate is converted to methylglyoxal by the action of the enzyme methylglyoxal synthase. The methylglyoxal generated is further reduced to either hydroxyacetone or lactaldehyde via two different routes. The formation of hydroxyacetone is catalyzed by the enzyme methylglyoxal reductase which is a primary alcohol dehydrogenase, while a secondary alcohol dehydrogenase such as glycerol dehydrogenase reduces methylglyoxal into lactaldehyde. Both hydroxyacetone and lactaldehyde can be further reduced to 1,2-propanediol by either a secondary alcohol dehydrogenase or a primary alcohol dehydrogenase. The dehydration of 1,2propanediol into 1-propanal can be achieved by a diol dehydratase. The conversion of 1-propanal to 1-propanol is also catalyzed by a primary alcohol dehydrogenase.

The pathway that leads to the synthesis of 1,2-propanediol has been introduced into both E. coli and Saccharomyces cerevisiae. By over-expressing the E. coli genes $m g s A$ and $g l d A$ and relying on the native expression of other enzymes, Altaras et al. achieved the production of $0.7 \mathrm{~g} / \mathrm{L}$ of 1,2-propanediol in E. coli [10]. $1.08 \mathrm{~g} / \mathrm{L} \mathrm{1,2-pro-}$ panediol production in E. coli was reported by BerriosRivera et al. by utlizing Clostridium acetobutylicum mgs $A$ and $E$. coli gldA in a strain defecient in lactate production and using an initial glucose concentration of $101.68 \mathrm{mM}$ [11]. Enhanced production of 1,2-propanediol in E. coli was also reported by Altaras et al. [12]. The study involved expression of more complete pathway by addition of fucO gene (1,2-propanediol oxidoreductase) responsible for the conversion of lactaldehyde to 1,2-propanediol and deletion of the competing pathway for lactate which involves the gene $l d h A$. Shake flask fermentation with the $l d h A$ - strain carrying the pathway led to the production of 1,2-propanediol at a titer of $1.27 \mathrm{~g} / \mathrm{L}$, while fed-batch fermentation gave a result of $4.5 \mathrm{~g} / \mathrm{L}$ of 1,2-propanediol. 1,2-propanediol production in S. cerevisiae was achieved by Joon-Young et al. [13]. Their strategy was based on the idea of channeling the carbon flux towards dihydroxyacetone phosphate with the deletion of triosphoshate isomerase in S. cerevisiae via triple homologous recombination. With the introduction of 1,2-propanediol pathways consisting of the E. coli genes $m g s A$ and $g l d A$, the engineered $S$. cerevisiae produced 1.11 $\mathrm{g} / \mathrm{L}$ of 1,2-propanediol compared to $0.89 \mathrm{~g} / \mathrm{L}$ produced from the strain lacking the gene tpil.

In this study, we first constructed the 1,2-propanediol pathway in the wild type E. coli strain BW25113 by expressing the genes, $m g s A$ from $B$. subtilis, budC from $K$. pneumoniae, and native $E$. coli $y d j G$, which resulted in the production of 1,2-propanediol at a titer of $0.8 \mathrm{~g} / \mathrm{L}$ in shake flasks. We further achieved the conversion of 1,2propanediol to 1-propanol via two successive enzymatic steps by expressing the operon ppdABC from $K$. oxytoca and using the native activity of $E$. coli alcohol dehydrogenases [14-16]. This established a new pathway for 1-propanol production by engineering the glycolytic pathway in E. coli.

\section{Results and Discussion \\ Methylglyoxal Synthase Assay}

1,2-Propanediol pathway branches from glycolysis and competes for the intermediate dihydroxyacetone phosphate, with the glycolytic pathway. The first enzyme of 1,2propanediol pathway, methylglyoxal synthase catalyzing irreversible conversion of dihydroxyacetone-phosphate to methylglyoxal holds paramount importance in channeling carbon flux towards 1,2-propanediol biosynthesis [10,11]. Highly active methylglyoxal synthase is therefore desirable. We screened the activity of methylglyoxal synthase from eight different sources. We amplified the $m g s A$ genes from the microorganisms: C. acetobutylicum (ATCC\# 824), B. subtilis 168, C. difficile R20291, E. coli MG1655, T. thermophilus HB27, K. pneumoniae MGH78578, P. fluorescens Pf-5, and R. eutropha H16 respectively. These genes were cloned and expressed in wild type E. coli BW25113 using eight plasmids pRJ1-pRJ8. Each gene was under the control of the IPTG-inducible pLlacO1 promoter. Using dihydroxyacetone-phosphate as the substrate, we successfully 


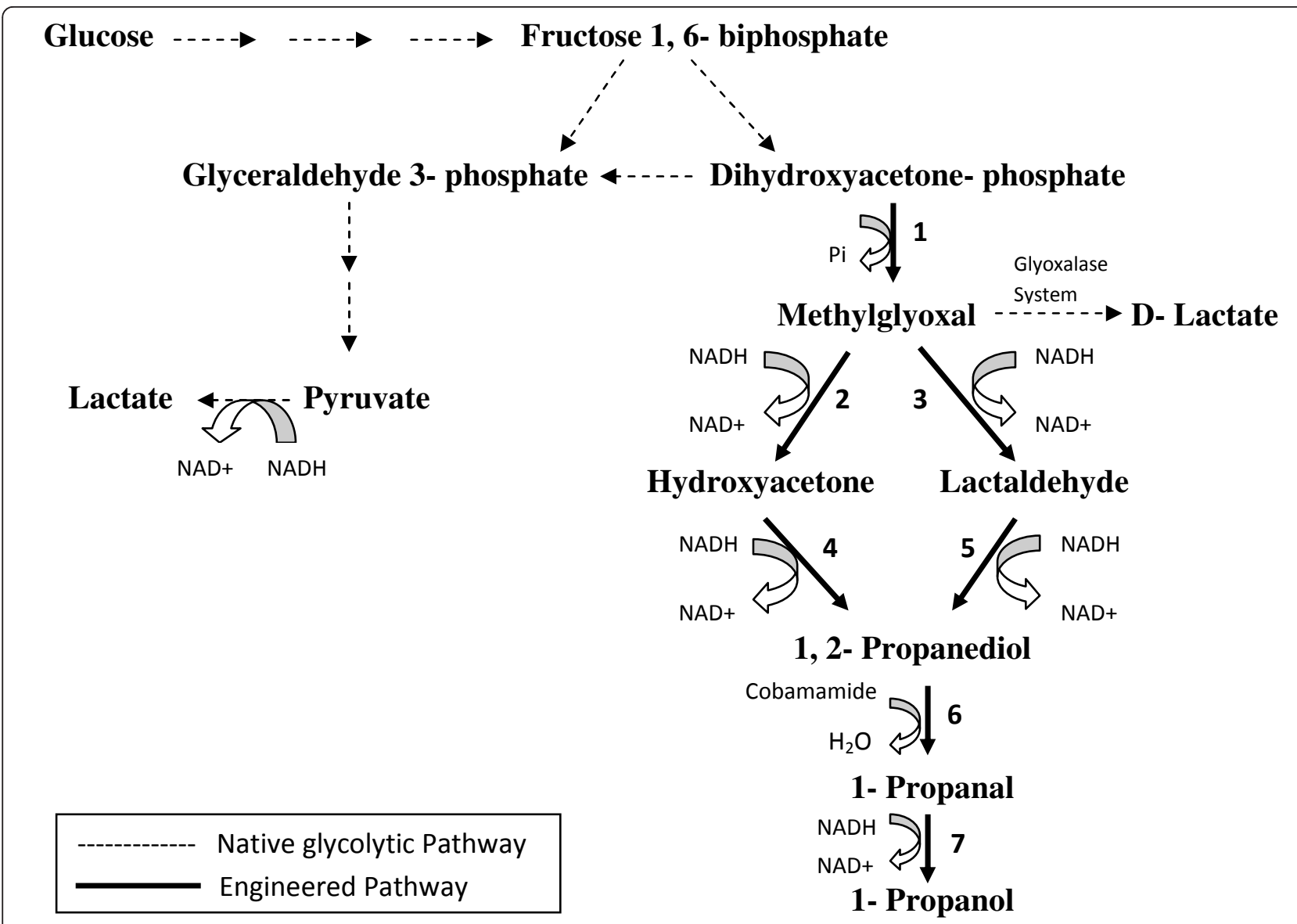

Figure 1 Designed metabolic pathway for 1,2-propanediol and 1-propanol production. Key enzymes 1: methylglyoxal synthase ( $m g s A) ; 2$ : methylglyoxal reductase (ydjG); 3, 4: secondary alcohol dehydrogenase (gldA/budC); 5: primary alcohol dehydrogenase (fucO); 6: diol dehydratase (ppdABC/gldABC/dhaB12); 7: primary alcohol dehydrogenase (yqhD).

detected the functional expression of all $m g s A$ genes in vitro, where the specific activities varied from $0.0052 \mathrm{U} / \mathrm{mg}$ to $0.1242 \mathrm{U} / \mathrm{mg}$ (Table 1 ). We identified most suitable methylglyoxal synthase as the $m g s A$ from $B$. subtilis demonstrating the highest ratio of specific activity $/ K_{m}$ $(0.1186)$ and having a specific activity of $0.0561 \mathrm{U} / \mathrm{mg}$. Without the over-expression of $m g s A$ gene, we also detected the native expression of $E$. coli $m g s A$, which gave a specific activity of only $0.0008 \mathrm{U} / \mathrm{mg}$, much lower than that of any over-expression.

\section{Methylglyoxal Reductase Assay}

We examined the activity of $E$. coli methylglyoxal reductase encoded by the gene $y d j G$ by using plasmid pRJ10. As a part of aldo-keto reductase family, the product of $y d j G$ executes a catalytic activity of reduction on methylglyoxal

Table 1 Methylglyoxal synthase assay results

\begin{tabular}{lccc}
\hline $\boldsymbol{m g} \boldsymbol{s}$ source & Specific Activity $(\mathbf{U} / \mathbf{m g})$ & $\boldsymbol{K}_{\boldsymbol{m}}(\mathbf{m M})$ & Specific Activity $/ \boldsymbol{K}_{\boldsymbol{m}}(\mathrm{U} / \mathbf{m g} / \mathbf{m M})$ \\
\hline C. acetobutylicum & $0.054 \pm 0.004$ & $0.776 \pm 0.005$ & 0.069 \\
B. subtilis & $\mathbf{0 . 0 5 6 \pm 0 . 0 0 3}$ & $\mathbf{0 . 4 7 3} \pm \mathbf{0 . 0 7}$ & $\mathbf{0 . 1 1 8}$ \\
C. difficile & $0.059 \pm 0.0 .003$ & $1.439 \pm 0.06$ & 0.041 \\
E. coli & $0.124 \pm 0.006$ & $1.418 \pm 0.12$ & 0.087 \\
T. thermophilus & $0.016 \pm 0.004$ & $2.118 \pm 0.07$ & 0.007 \\
K. pneumoniae & $0.016 \pm 0.009$ & $2.820 \pm 0.3$ & 0.005 \\
P. fluorescens & $0.013 \pm 0.008$ & $1.560 \pm 0.02$ & 0.008 \\
R. eutropha & $0.005 \pm 0.000$ & $0.700 \pm 0.03$ & 0.007 \\
\hline
\end{tabular}

Substrate dihydroxyacetone phosphate concentration was varied from $0.15 \mathrm{mM}$ to $1.5 \mathrm{mM}$ for all reactions. 1 unit (U) was defined as the amount ( $\mu$ moles) of methylglyoxal formed per unit time (min). 
using NADH to generate hydroxyacetone[17]. We determined both the specific activity and substrate affinity of E. coli methylglyoxal reductase on methylglyoxal. When the gene is over-expressed by pRJ10, the specific activity was determined to be $1.62 \pm 0.012 \mathrm{U} / \mathrm{mg}$. The enzyme also showed sufficient substrate specificity with a $K_{m}$ value of $3.31 \pm 0.02 \mathrm{mM}$.

\section{Secondary Alcohol Dehydrogenase Assay}

The synthesis of 1,2-propanediol from methylglyoxal occurs through two different pathways. For the pathway via lactaldehyde leading to 1, 2-propanediol formation we evaluated the activities of two NADH dependent secondary alcohol dehydrogenases: $E$. coli glycerol dehydrogenase ( gldA) and K. pneumoniae diol dehydrogenase (budC) on methylglyoxal. We also tested the catalytic properties of these two secondary alcohol dehydrogenases on hydroxyacetone for the completion of the other pathway.

The genes $g l d A$ and $b u d C$ were cloned and expressed in $E$. coli using the plasmid pRJ9 and pYY109. The specific activity and $K_{m}$ value of glycerol dehydrogenase and diol dehydrogenase were determined for the substrates methylglyoxal and hydroxyacetone. Both enzymes showed dehydrogenation activity leading to the conversion of methylglyoxal to lactaldehyde and hydroxyacetone to 1,-2propanediol. Table 2 provides the results of this assay. The diol dehydrogenase and glycerol dehydrogenase reduced both methylglyoxal and hydroxyacetone. When methylglyoxal was used as the substrate, the diol dehydrogenase demonstrated a specific activity of $3.718 \mathrm{U} / \mathrm{mg}$ with a $K_{m}$ value of $0.78 \mathrm{mM}$; while the glycerol dehydrogenase showed both lower specific activity $(2.456 \mathrm{U} / \mathrm{mg})$ and substrate affinity $\left(K_{m}=68.24 \mathrm{mM}\right)$. Similar results were observed when hydroxyacetone was tested as a substrate, the diol dehydrogenase more efficiently reduced hydroxyacetone into 1,2-propanediol (specific activity $=4.97 \mathrm{U} / \mathrm{mg}$; $K_{m}=1.83 \mathrm{mM}$ ) compared with the glycerol dehydrogenase (specific activity $=0.912 \mathrm{U} / \mathrm{mg} ; K_{m}=10.47 \mathrm{mM}$ )

\section{Propanediol Dehydratase in vivo Assay}

The diol dehydratases we tested included a propanediol dehydratase (PPD) originating in $K$. oxytoca, a glycerol dehydratase (GLD) from K. pneumoniae, and a glycerol dehydratase (GLD) from C. butyricum. The PPD of K. oxytoca and the GLD of $K$. pneumoniae are iso-functional enzymes which catalyze the coenzyme B12-depedent conversion of 1,2-propanediol or glycerol to the corresponding aldehyde [17-20]. These enzymes have been utilized to develop a biological process to produce 1,3-propanediol from glycerol [21]. Each of these enzymes consists of three subunits encoded by three structural genes ( $p p d A B C$ or $g l d A B C)$. Although the catalytic site is hosted by subunit $A$, the presence of subunits $B$ and $C$ are obligatory for enzyme activity [19]. In order to evaluate their catalytic efficiency towards 1,2-propanediol, all three subunits were co-expressed in $E$. coli to reconstitute the enzymes using the plasmids pYY93 and pYY134. The GLD from C. butyricum is a coenzyme B12-independent diol dehydratase comprised of two subunits encoded by dhaB12, which only demonstrates activity under strict anaerobic conditions [21]. To evaluate its catalytic efficiency, we constructed the plasmid pYY167 to co-express these two units.

The formation of 1-propanol from 1,2-propanediol involves two enzymatic steps. For the first step we evaluated the dehydration activity of three different diol dehydratases for the generation of 1-propanal. For the second step we relied on the native alcohol dehydrogenase activity of E. coli to convert the generated 1-propanal to 1-propanol. An experiment was designed and conducted as we described to perform the in vivo enzyme assay of propanediol dehydratase and also to evaluate the native activity of $E$. coli for the final step. Whole-cell bioconversion studies using wild type E. coli strain BW25113 carrying pYY93, pYY134, and pYY167 respectively were conducted in shake flasks by feeding $5 \mathrm{~g} / \mathrm{L}(65.7 \mathrm{mM})$ 1,2-propanediol as the substrate. The samples were collected after 24 hours and analyzed by HPLC-RID.

The results are presented in Figure 2. The catalytic efficiency of $K$. oxytoca PPD was the highest among all, producing $65.6 \mathrm{mM}$ 1-propanol amounting to nearly $100 \%$ conversion. This result also indicated that the native expression of alcohol dehydrogenases in E. coli is sufficient to convert 1-propanal to 1-propanol completely. Over-expression of the alcohol dehydrogenases will not be necessary for 1-propanol production in E. coli. The K. pneumoniae GLD and C. butyricum GLD only demonstrated about $60.9 \%$ and $30.9 \%$ of the catalytic efficiency of $K$. oxytoca PPD, producing $39.99 \mathrm{mM}$ and $20.35 \mathrm{mM}$ 1-propanol, respectively.

Table 2 Specific activity and $K_{m}$ determination of the secondary alcohol dehydrogenases

\begin{tabular}{ccccc}
\hline Gene & \multicolumn{2}{c}{ Methylglyoxal } & \multicolumn{2}{c}{ Hydroxyacetone } \\
\cline { 2 - 5 } & $\begin{array}{c}\text { Specific Activity } \\
(\mathbf{U} / \mathbf{m g})\end{array}$ & $\begin{array}{c}\boldsymbol{K}_{\boldsymbol{m}} \\
(\mathbf{m M})\end{array}$ & $\begin{array}{c}\text { Specific Activity } \\
(\mathbf{U} / \mathbf{m g})\end{array}$ & $\begin{array}{c}\boldsymbol{K}_{\boldsymbol{m}} \\
(\mathbf{m M})\end{array}$ \\
\hline g/dA & $2.45 \pm 0.00$ & $68.24 \pm 0.05$ & $0.91 \pm 0.00$ & $10.47 \pm 0.55$ \\
budC & $3.71 \pm 0.06$ & $0.78 \pm 0.03$ & $4.97 \pm 0.00$ & $1.83 \pm 0.63$ \\
\hline
\end{tabular}

The decrease in absorbance of $\mathrm{NADH}$ at $340 \mathrm{~nm}$ was recorded and used for calculations using the substrates methylglyoxal and hydroxyacetone. Substrate concentration was varied from $20 \mathrm{mM}-120 \mathrm{mM}$. 1 unit (U) was defined as the amount ( $\mu$ moles) of product formed per unit time (min). 


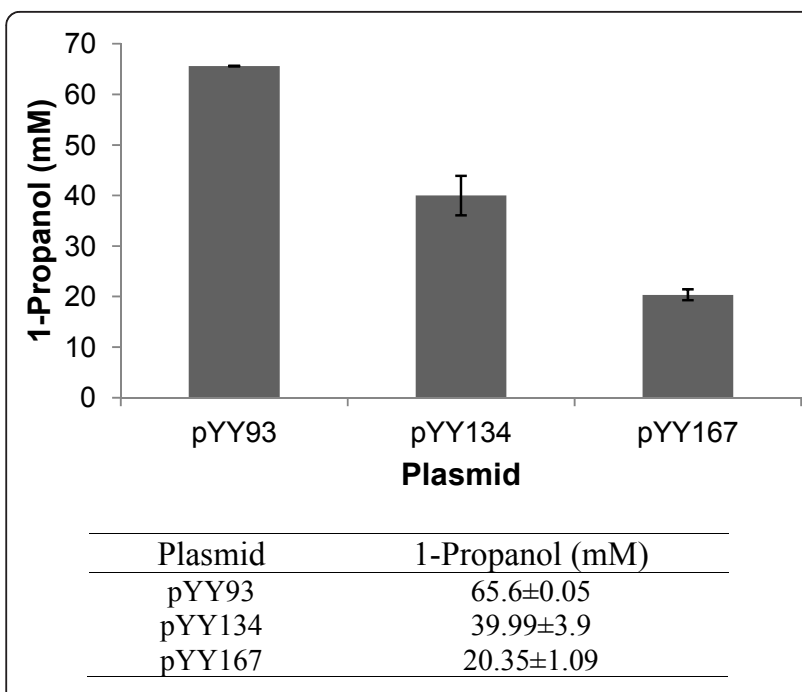

Figure 2 The results of in vivo enzyme assay of diol dehydratase using $5 \mathrm{~g} / \mathrm{L}(65.7 \mathrm{mM})$ 1,2-propanediol as the substrate.

Production of 1,2-Propanediol and 1-Propanol in E. coli In order to introduce the 1-propanol pathway into wild type E. coli strain BW25113, we constructed two plasmids. The first plasmid pRJ11 carries the genes encoding the most active enzymes for 1,2-propanediol biosynthesis. Specifically, $m g s A$ from $B$. subtilis, ydjG from E. coli, and budC from $K$. pneumoniae were organized as a synthetic operon under the control of IPTG-inducible pLlacO1 promoter in a high-copy number plasmid. The second plasmid pYY93 contains only the structural genes $p p d A B C$ encoded by $K$. oxytoca PPD. For the enzymatic steps of lactaldehyde to 1,2-propanediol and 1-propanal to 1-propanol, we completely relied on the native expression of alcohol dehydrogenases in E. coli, as is indicated to be sufficient $[10,11]$. We also evaluated M9 media in comparison to low-phosphate media for the production of 1,2-propnaediol (Data not provided). The results of an initial experiment show significant increase in production using low-phosphate media. Using M9 media resulted in only about $0.1 \mathrm{~g} / \mathrm{L}$ of 1,2-propanediol generation after 48 hours of anaerobic fermentation compared to about $0.8 \mathrm{~g} / \mathrm{L}$ from low-phosphate media. Hence low-phosphate media was used for all fermentation studies. The culture conditions were the same as described in "Methods and Materials".

We first transformed the plasmid pRJ11 into wild type $E$. coli strain BW25113 to achieve 1,2-propanediol production. It has been reported that the enzyme methylglyoxal synthase is inhibited by phosphate ion [22,23]. The inhibition of methylglyoxal synthase would result in the carbon flux being diverted to glyceraldehyde-3-phosphate instead of methylglyoxal by the conversion action of triose phosphate isomerase. Therefore a low-phosphate media was employed to avoid this problem. The fermentation experiments were conducted in $20 \mathrm{ml}$ cultures as described in the "Methods and Materials". The fermentation samples were collected after 24 hours and 48 hours and analyzed by HPLC-RID. As the results shown in Table 3, after 24 hours $0.66 \mathrm{~g} / \mathrm{L} 1,2$-propanediol was produced. The production reached $0.80 \mathrm{~g} / \mathrm{L}$ after 48 hours. Lactate was detected as the dominant by-product and was accumulated at over $7 \mathrm{~g} / \mathrm{L}$. We also conducted the experiments aerobically. However, only a trace amount $(<0.01 \mathrm{~g} / \mathrm{L})$ of 1,2-propanediol was produced and the cell growth was much better than in anaerobic conditions, which indicates that glycolysis is very active in aerobic condition and drags almost all carbon flux towards pyruvate for cell growth or other cell activities.

With the successful establishment of the pathways for 1 , 2-propanediol production using pRJ11, we hypothesized that the co-expression of pRJ11 with pYY93 would result in the production of 1-propanol. To test this, wild type E. coli BW25113 was transformed with both pRJ11 and pYY93 for 1-propanol production by electroporation. The fermentation condition was similar to that used for 1,2-propanediol production with the addition of $10 \mu \mathrm{M}$ coenzyme B-12 to the culture along with IPTG $(0.1 \mathrm{mM})$ after 6 hours. After 24 hours, the double transformed strain produced $0.11 \mathrm{~g} / \mathrm{L} 1$-propanol with $0.44 \mathrm{~g} / \mathrm{L} 1,2$ propanediol remaining unconverted (Table 3). After 48 hours, 1-propanol was produced at $0.25 \mathrm{~g} / \mathrm{L}$ with $0.46 \mathrm{~g} / \mathrm{L}$ 1,2-propanediol remaining unconverted. The major byproduct was again lactate at over $7 \mathrm{~g} / \mathrm{L}$.

\section{Conclusions}

We have successfully established a new pathway for 1-propanol production by shunting the native glycolytic pathway in E. coli. The addition of the coenzyme B-12 dependent propanediol dehydratase from $K$. oxytoca resulted in the conversion of 1,2-propanediol to 1-propanal which was then dehydrogenated by $E$. coli native activity to 1 propanol.

From the assay of methylglyoxal synthase it was determined that the mgsA from B. subtilis was the most active. Since the accumulation of methylglyoxal in high quantities is toxic to the cell [24], it is important that the generated methylglyoxal is immediately converted to another metabolite by the downstream enzymes in the pathway.

\begin{tabular}{|c|c|c|c|c|}
\hline \multirow[t]{2}{*}{ Plasmid } & \multicolumn{2}{|c|}{ 1, 2-Propanediol (g/L) } & \multicolumn{2}{|c|}{ 1-Propanol $(\mathrm{g} / \mathrm{L})$} \\
\hline & $24 \mathrm{~h}$ & $48 \mathrm{~h}$ & $24 \mathrm{~h}$ & $48 \mathrm{~h}$ \\
\hline pRJ11 & $0.66 \pm 0.01$ & $0.80 \pm 0.01$ & $-\ldots$ & -—- \\
\hline pRJ11 and pYY93 & $0.44 \pm 0.01$ & $0.46 \pm 0.02$ & $0.11 \pm 0.01$ & $0.25 \pm 0.07$ \\
\hline
\end{tabular}


To address this problem we screened the activity of methylglyoxal reductase and two secondary alcohol dehydrogenases.

To evaluate 1, 2-propanediol formation, methylglyoxal synthase ( $m g s A)$ from $B$. subtilis and propanediol dehydratase (budC) from $K$. pneumoniae were expressed leading to the conversion of dihydroxyacetone phosphate to 1,2propanediol via the formation of methylglyoxal and lactaldehyde. To strengthen our constructed pathway the introduction of E. coli methylglyoxal reductase ( $y d j G)$, a dual metabolic route for production of 1, 2-propanediol was established for the first time. This resulted in channeling the carbon flux from methylglyoxal to hydroxyacetone and 1,2-propanediol. Fermentation with E. coli BW25113 transformed with pRJ11 carrying the three above mentioned genes produced $0.8 \mathrm{~g} / \mathrm{L}$ 1,2-propanediol after 48 hours of anaerobic fermentation.

We also evaluated the use of a medium copy number vector (pRJ12) for 1, 2-propanediol production (data not provided). This was done using the same genes used for the construction of high copy number plasmid pRJ11 but in the backbone of a medium copy number vector pCS27. However, the production of 1, 2-propanediol from a medium copy number vector (pRJ12) was found to be significantly lower than the production by high copy number vector (pRJ11). Hence the medium copy number vector was not selected for 1, 2-propanediol and 1-propanol production.

The result of the in vivo enzyme assay (Figure 2) shows almost $100 \%$ conversion of 1, 2-propanediol to 1-propanol indicating that the conversion of 1,2-propanediol to 1 -propanal was very efficient and that the native expression of alcohol dehydrogenases in $E$. coli is sufficient in converting 1-propanal to 1-propanol. However, it was not the case for the strain carrying the plasmids pRJ11 and pYY93 which showed much lower conversion of 1,2propanediol to 1 -propanol as about $0.46 \mathrm{~g} / \mathrm{L}$ of 1,2 -propanediol was left unconverted. We speculate that the reason for this could be the expression issue of $p p d A B C$. The optimal expression of these three subunits can be successfully achieved in aerobic conditions as we did in in vivo assay [19]. However, in anaerobic conditions which is required for 1,2-propanediol production, the protein expression might be negatively affected due to low cellular energy and nutrients. Such a problem could be resolved in a more controlled environment such as in a bench scale fermenter by the delicate adjustment of oxygen level during fermentation course.

The accumulation of $7 \mathrm{~g} / \mathrm{L}$ lactate indicates that the carbon flux towards pyruvate is still strong in anaerobic conditions. The main branch of glycolysis plays the major role. Theoretically, one molecule of fructose-1,6-bisphosphate is broken down into one molecule of glyceraldehyde-3-phosphate and one molecule of dihydroxyacetone phosphate [25]. However, the presence of triose phosphate isomerase seems to channel the carbon flux back to the main branch toward pyruvate biosynthesis [25]. In addition, the pentose phosphate pathway is also very active in low phosphate conditions [26]. This pathway does not generate dihydroxyacetone phosphate as an intermediate, but directly goes to pyruvate. The pyruvate generated is acted upon by lactate dehydrogenase $(l d h A)$ resulting in the production of lactate [27]. Another minor route of lactate formation is via the glyoxalase pathway where methylglyoxal is converted to lactate by the native expression of gloA [28].

Overall, the work presented here represents 1-propanol production in a wild type E. coli strain and forms a basis for further enhancement in production. The effect of competing pathways is significant and the deletion of the same has not been explored in this study. We speculate that by the knock-out of genes encoding for lactate dehydrogenase $(l d h A)$, glyoxalaseI $(g l o A)$ and other competing pathways (tpiA and $z w f$ ) the production of 1-propanol can be further enhanced, which will be pursued in the near future.

\section{Materials and methods}

\section{Chemicals and Reagents}

Hydroxyacetone was bought from Acros Organics (New Jersey, USA); methylglyoxal and 1,2-propanediol were purchased from Sigma Aldrich (St. Louis, Mo); 1-propanol was obtained from Fisher Scientific (Atlanta, GA). KOD DNA polymerase was obtained from EMD Chemicals Inc., NJ. All restriction enzymes were bought from New England Biolabs (Beverly, MA). The rapid DNA ligase was obtained from Roche Applied Science (Indianapolis, IN). All the enzymes were used according to the instructions of the manufacturer.

\section{Plasmids and Strains}

E. coli strain XL1-Blue (Stratagene, CA) was used for DNA manipulations; while wild type E. coli strain BW25113 (E. coli Genetic Resource Center, CT) and E. coli strain BL21* (Invitrogen) were employed for enzyme assays and shake flask experiments. Plasmids pZE12-luc [29], pCS27 [7] and pCDF-Duet1 (EMD Chemicals Inc., NJ) were used for DNA cloning. The features and descriptions of the used strains and plasmids are listed in Table 4.

\section{DNA manipulations}

All DNA manipulations were performed according to the standard procedures as described previously [30]. The primers involved in DNA manipulations are listed in Table 5. The plasmids listed in Table 4 were constructed as described below.

For the methylglyoxal synthase assay, the plasmids pRJ1-pRJ8 were constructed by cloning $m g s A$ genes from eight different sources into the vector pZE12-luc 
Table 4 List of strains and plasmids used in this study

\begin{tabular}{|c|c|c|}
\hline Strain & Genotype & Reference \\
\hline E. coli BW25113 & rrnBT14 DlacZWJ16 hsdR514 DaraBADAH33 DrhaBADLD78 & [32] \\
\hline E. coli BL21* & F ompT hsdS $S_{B}\left(r_{B}^{-} m_{B}^{-}\right) \mathrm{gal} d c m(D E 3)$ & Invitrogen \\
\hline E. coli XL-1 Blue & recA1 endA1gyrA96thi-1 hsdR17supE44relA1lac [F' proAB laclaZDM15Tn10 (TetR)] & Stratagene \\
\hline Plasmid & Description & Reference \\
\hline pZE12-luc & pLlacO1::Iuc(VF); ColE1 ori; $A m p^{R}$ & [29] \\
\hline pCS27 & pLlacO1:: MCS; p15A ori; Kan ${ }^{R}$ & [7] \\
\hline pCDF-Duet1 & pT7lac::MCS;CDF ori; $S m^{R}$ & EMD Chemicals Inc., NJ \\
\hline pYY93 & ppdABC from K. oxytoca cloned into pCS27 & This study \\
\hline pYY109 & budC from K. pneumoniae cloned into pCDF-Duet1 & This study \\
\hline pYY134 & gldABC from K. pneumoniae cloned into pCS27 & This study \\
\hline pYY167 & dhab12 from C. butyricum cloned into pCS27 & This study \\
\hline pRJ1 & mgsA from C. acetobutylicum cloned into pZE12-luc & This study \\
\hline pRJ2 & mgsA from B. subtilis cloned into pZE12-luc & This study \\
\hline pRJ3 & mgsA from C. difficile cloned into pZE12-luc & This study \\
\hline pRJ4 & mgsA from E. coli cloned into pZE12-luc & This study \\
\hline pRJ5 & mgsA from $T$. thermophilus cloned into pZE12-luc & This study \\
\hline pRJ6 & mgsA from K. pneumoniae cloned into pZE12-luc & This study \\
\hline pRJ7 & mgsA from $P$. fluorescens cloned into pZE12-luc & This study \\
\hline pRJ8 & mgsA from R. eutropha cloned into pZE12-luc & This study \\
\hline pRJ9 & gldA from E. coli cloned into pZE12-luc & This study \\
\hline pRJ10 & ydjG from E. coli cloned into pZE12-luc & This study \\
\hline pRJ11 & $\begin{array}{l}\text { ydjG from E. coli, budC from K. pneumoniae, and mgsA } \\
\text { from B. subtilis cloned in pZE12-luc }\end{array}$ & This study \\
\hline
\end{tabular}

separately. Using the primers listed in Table 5, the $m g s A$ genes were PCR amplified from the genomic DNA of $C$. acetobutylicum (ATCC824), B. subtilis 168, Clostridium difficile R20291, E. coli MG1655, Thermus thermophilus HB27, K. pneumoniae MGH78578, Pseudomonas fluorescens Pf-5, and Ralstonia eutropha H16 respectively. The DNA fragments obtained were digested with restriction enzymes for three hours. Acc65I and SphI restriction enzymes were used to digest $m g s A$ genes from C. acetobutylicum (ATCC824), B. subtilis 168, C. difficile R20291, E. coli MG1655, T. thermophilus HB27, K. pneumoniae MGH78578, BsrGI and SphI for the mgs A from P. fluorescens Pf-5, and Acc65I and XbaI for the $m g s A$ from $R$. eutropha H16. The vector pZE12-luc was also digested with the appropriate restriction enzymes for the above mentioned eight genes. The digested genes were then inserted into the vector pZE12-luc separately.

In order to determine the activity of methylglyoxal reductase, the plasmid pRJ10 was constructed. The $y d j G$ gene PCR amplified from E. coli MG1655 was cloned into pZE-12luc with restriction enzymes Acc65I and XbaI generating pRJ10. For the assay of secondary alcohol dehydrogenases, plasmids pRJ9 and pYY109 were constructed. The gldA gene from E. coli MG1655 was inserted into pZE12-luc vector using restriction enzymes SphI and XbaI for the construction of plasmid pRJ9. We created pYY109 by inserting the budC gene from $K$. pneumoniae MGH78578 into pCDF-Duet1 vector. The restriction enzymes used for the construction of plasmid pYY109 were BamHI and SalI.

For diol dehydratase assay, plasmids pYY93, pYY134, and pYY167 were constructed. The ppdABC operon obtained via PCR from the genomic DNA of $K$. oxytoca was digested with restriction enzymes BsiWI and HindIII and inserted into plasmid pCS27 digested by BsiWI and HindIII. Similarly, the gldABC operon was PCR amplified from genomic DNA of K. pnuemoniae MGH 78578 and inserted into pCS27 using restriction enzymes Acc65I and HindIII. To construct pYY167, we first synthesized the operon dhaB12 from Clostridium butyricum by a PCR assembly of $50 \mathrm{bp}$ oligonucleotides designed from Helix Systems (NIH). The codons were optimized for E. coli standard expression. The operon was cloned into pCS27 using Acc65I and HindIII, forming pYY167.

Following the enzyme assays, plasmid pRJ11 was constructed using the most active enzymes in order to produce 1, 2-propanediol. The plasmid pRJ11 was generated via the ligation of three genes on the backbone of pZE12luc vector. The genes $y d j G, b u d C$ and $m g s A$ were PCR amplified using the primers listed in Table 5 from the genomic DNA of E. coli MG1655, K. pnuemoniae MGH78578 and B. subtilis 168, respectively. Following this, the PCR amplified $y d j G$ gene product was digested 
Table 5 Primers used in this study.

\begin{tabular}{|c|c|c|}
\hline Plasmid & Gene & Primer Sequence $\left(5^{\prime}-3^{\prime}\right)$ \\
\hline pRJ1 & mgsA & $\begin{array}{l}\text { F: GGGAAAGGTACCATGGCACTTATAATGAATAGTAAAAAAAAGATAGC } \\
\text { R: GGGAAA GCATGCTTAAAAATTGTCTITCTAATIIITGGTAATAAT }\end{array}$ \\
\hline pRJ2 & mgsA & 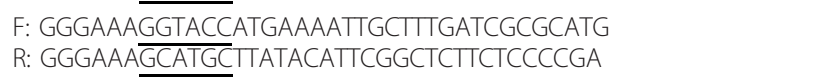 \\
\hline pRJ3 & $m g s A$ & 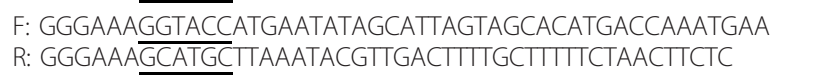 \\
\hline pRJ4 & mgsA & $\begin{array}{l}\text { F: GGGAAAGGTACCATGGAACTGACGACTCGCAC } \\
\text { R: GGGAAAGCATGC TTACTTCAGACGGTCCGCGA }\end{array}$ \\
\hline pRJ5 & mgsA & $\begin{array}{l}\text { F: GGGAAAGGTACCATGCCCATGAAGGCCCTGGC } \\
\text { R: GGGAAA } \overline{\text { GCATGCCTATTGGGGGGTTCCCTTGC }}\end{array}$ \\
\hline pRJ6 & mgsA & $\begin{array}{l}\text { F: GGGAAAGGTACCATGTGGAATGAAAATATGGAACTGACAACACGTAC } \\
\text { R: GGGAAAGCATGCTTATTTCAGGCGCTCGGCAA }\end{array}$ \\
\hline pRJ7 & mgsA & $\begin{array}{l}\text { F: GGGAAATGTACAATGATCGGTATCAGTTCACCC } \\
\text { R: GGGAAA } \overline{\overline{G C A T G C}} \text { TATCCTCGGCCGGCCAGGTA }\end{array}$ \\
\hline pRJ8 & mgsA & $\begin{array}{l}\text { F: GGGAAAGGTACCATGACTCGCCCCCGCATCGCGTTGAT } \\
\text { R: GGGAAATCTAGATCAGCTGGCCGCCGCTTCGT }\end{array}$ \\
\hline pRJ9 & gldA & $\begin{array}{l}\text { F: GGGAAAGCATGCAGGAGATATACCATGGACCGCATTATTCAATCACCGG } \\
\text { R: GGGAAATCTAGATTATTCCCACTCTTGCAGGAAACGC }\end{array}$ \\
\hline pRJ10 & ydjG & $\begin{array}{l}\text { F: GGGAAAGGTACCATGAAAAAGATACCTTAGGCACAACGG } \\
\text { R: GGGAAATCTAGATTAACGCTCCAGGGCCTCTGCCATTTCC }\end{array}$ \\
\hline pRJ11 & $\begin{array}{l}\text { ydjG } \\
\text { budC } \\
\text { mgsA }\end{array}$ & 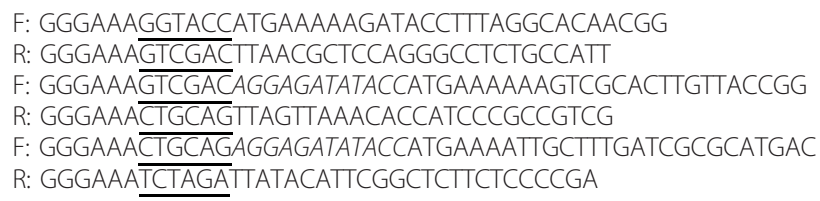 \\
\hline pYY93 & ppdABC & 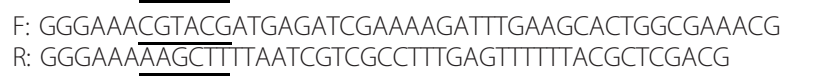 \\
\hline pYY109 & budC & $\begin{array}{l}\text { F: GGGAAAGGATCCGAAAAAAGTCGCACTTGTAACCGGCG } \\
\text { R: GGGAAAGTCGACTAGTTAAACACCATCCCGCCGTCG }\end{array}$ \\
\hline pYY134 & gld $A B C$ & 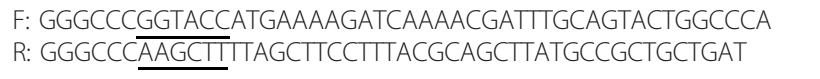 \\
\hline pYY167 & dhaB12 & $\begin{array}{l}\text { F: GGGAAAGGTACCATGATCAGCAAAGGGTTCAGCACCCAG } \\
\text { R: GGGAAA } \overline{A A G C T T I T A T T C C G C G C C T A T A G T A C A C G G A A T G C C C A T A A ~}\end{array}$ \\
\hline
\end{tabular}

Underlined nucleotides represent restriction sites. Italicized nucleotides represent ribosome binding sites inserted in the primer.

with Acc65I and SalI. The PCR amplified budC gene product was digested with SalI and PstI, and the PCR amplified $m g s A$ gene was digested with PstI and XbaI. Vector pZE12-luc was digested with Acc65I and XbaI. After digestion for three hours, the three gene fragments and the vector were ligated simultaneously, creating pRJ11. It should be noted that RBS sequence (AGGAGA) was inserted upstream of each structure gene with 6-8 nucleotides in between to facilitate protein translations.

\section{Culture Medium and Fermentation Conditions}

M9 minimum was used for the in-vivo assay of propanediol dehydratase and low-phosphate minimum medium was used for shake flask fermentations. M9 minimum media consisted of (per liter): $20 \mathrm{~g}$ glucose, $5 \mathrm{~g}$ yeast extract, $12.8 \mathrm{~g} \mathrm{Na}_{2} \mathrm{HPO}_{4} .7 \mathrm{H}_{2} \mathrm{O}, 3 \mathrm{~g} \mathrm{KH}_{2} \mathrm{PO}_{4}, 0.5 \mathrm{~g} \mathrm{NaCl}$, $1 \mathrm{~g} \mathrm{NH}_{4} \mathrm{Cl}, 0.5 \mathrm{mM} \mathrm{MgSO}_{4}$, and $0.05 \mathrm{mM} \mathrm{CaCl}_{2}$. The low-phosphate media consisted of (per liter): $20 \mathrm{~g}$ glucose, $5 \mathrm{~g} \mathrm{NaCl}, 5 \mathrm{~g}$ yeast extract, $1.5 \mathrm{~g} \mathrm{KCl}, 1 \mathrm{~g} \mathrm{NH}_{4} \mathrm{Cl}, 0.2 \mathrm{~g}$ $\mathrm{MgCl}_{2}, 0.07 \mathrm{~g} \mathrm{Na}_{2} \mathrm{SO}_{4}$, and $0.005 \mathrm{~g} \mathrm{FeCl}_{3}$, which was buffered to $\mathrm{pH} 6.8$ with $13.3 \mathrm{~g}$ of $\mathrm{NaHCO}_{3}$ and $10 \mathrm{~g}$ of 3[N-morpholino] propanesulfonic acid (MOPS) $[10,12]$.

For the shake flask fermentations, $1 \mathrm{~mL}$ of seed culture was prepared in LB media containing necessary antibiotics and grown overnight at $37^{\circ} \mathrm{C}$ in a shaker set at $250 \mathrm{rpm}$. After overnight incubation, the culture was inoculated into $20 \mathrm{~mL}$ of $\mathrm{M} 9$ or low-phosphate media containing appropriate antibiotics in $150 \mathrm{~mL}$ serum bottles. After growing at $37^{\circ} \mathrm{C}$ for 3 hours, the cultures were switched to an anaerobic condition by sparging nitrogen gas. IPTG was added into the culture to a final concentration of 0.1 $\mathrm{mM} 6$ hours after inoculation to induce protein expression. Then the fermentation was carried out at $30^{\circ} \mathrm{C}$ at $250 \mathrm{rpm}$. Samples were taken after 24 and 48 hours and analyzed with HPLC-RID.

\section{HPLC-RID Analysis}

The analysis of fermentation products was done via HPLC (Shimadzu) equipped with a Coregel-64H column (Transgenomic). $1 \mathrm{~mL}$ sample was collected and centrifuged at 
$15,000 \mathrm{rpm}$ for 10 minutes and the supernatant was filtered and used for analysis. The mobile phase used was 4 $\mathrm{mN} \mathrm{H}_{2} \mathrm{SO}_{4}$ having a flow rate of $0.6 \mathrm{~mL} / \mathrm{min}$ and an oven temperature set at $60^{\circ} \mathrm{C}$ [31].

\section{Enzyme Crude Extract Preparation}

E. coli strain BL21* was employed to express budC carried by pYY109. Expression of other individual enzymes was conducted in the wild type E. coli strain BW25113 harboring the corresponding plasmids. Generally, the transformed strains were pre-inoculated into LB liquid medium containing appropriate antibiotics and grown at $37^{\circ} \mathrm{C}$ overnight with shaking. The following day, $1 \mathrm{~mL}$ of preinoculum was added to $50 \mathrm{~mL}$ of fresh LB medium containing necessary antibiotics. The culture was left to grow at $37^{\circ} \mathrm{C}$ with shaking until the $\mathrm{OD}_{600}$ reached approximately 0.6. At that point, IPTG was added to a final concentration of $1 \mathrm{mM}$ and the protein expression was conducted at $30^{\circ} \mathrm{C}$ for 3 hours. The cells were collected by centrifugation at $5000 \mathrm{rpm}$ for $10 \mathrm{~min}$ at $4^{\circ} \mathrm{C}$. The cell pellets were resuspended in $2 \mathrm{~mL}$ of $50 \mathrm{mM}$ imidazole- $\mathrm{HCl}$ buffer ( $\mathrm{pH} 7.0$ ). Cell disruption was performed using French Press, and soluble protein was obtained by ultra-centrifugation for enzyme assays. Total protein concentration was estimated using the BCA kit (Pierce Chemicals).

\section{Methylglyoxal Synthase Assay}

Methylglyoxal synthase assay was performed as described previously with minor revisions $[10,11,23]$. The assay was carried out using a two step procedure. The reaction mixture $(500 \mu \mathrm{l})$ consisted of $50 \mathrm{mM}$ imidazole- $\mathrm{HCl}$ buffer ( $\mathrm{pH} 7.0$ ), 0.15-1.5 mM dihydroxyacetone phosphate, and $25 \mu \mathrm{l}$ crude extract. Reaction was started with the addition of $25 \mu \mathrm{l}$ crude extract to the reaction mixture and incubated in a water bath at $30^{\circ} \mathrm{C}$ for 30 seconds. Followed by this, the reaction was immediately stopped by the addition of $30 \mu \mathrm{l}$ sample of the reaction mixture to the detection mixture and incubated in a water bath at $30^{\circ} \mathrm{C}$ for $15 \mathrm{~min}$ utes. The detection mixture consisted of $300 \mu \mathrm{l}$ of DI water, $110 \mu \mathrm{l}$ of $0.1 \%$ 2, 4-dinitrophenylhydrazine dissolved in $2 \mathrm{~N} \mathrm{HCl}$. After the completion of 15 minutes $550 \mu \mathrm{l}$ of $10 \% \mathrm{NaOH}$ was added to the detection mixture and then incubated at room temperature for another 15 minutes. (Final volume of detection mixture $=990 \mu \mathrm{l}$ ). The samples were diluted 10 times before measuring the absorbance at $550 \mathrm{~nm} .1 \mu \mathrm{mol}$ of methylglyoxal has an absorbance value of 16.4 at $550 \mathrm{~nm}$ [11].

\section{Methylglyoxal reductase assay}

The reaction mixture contained 20-120 mM methylglyoxal and $0.25 \mathrm{mM} \mathrm{NADH}$, in imidazole- $\mathrm{HCl}$ buffer ( $\mathrm{pH}$ 7.0) having a final volume of $970 \mu \mathrm{l}$. The assay was begun with the addition of $30 \mu \mathrm{l}$ crude extract to the reaction mixture. The reaction was allowed to proceed for 60 seconds at $37^{\circ} \mathrm{C}$. We measured the decrease in absorbance of NADH at $340 \mathrm{~nm}$ to calculate the specific activity $[10,11]$.

\section{Secondary Alcohol Dehydrogenase Assay}

The enzyme crude extracts prepared from gldA and budC expression were used for this assay. The reaction mixture consisted of 20-120 mM of methylglyoxal or hydroxyacetone and $0.25 \mathrm{mM} \mathrm{NADH}$ in imidazole- $\mathrm{HCl}$ buffer at ( $\mathrm{pH} 7.0)$ with a final volume of $970 \mu \mathrm{l}$. The assay was begun with the addition of $30 \mu \mathrm{l}$ crude extract to the reaction mixture. The reaction was allowed to proceed for 60 seconds at $37^{\circ} \mathrm{C}$. We measured the decrease in absorbance of $\mathrm{NADH}$ at $340 \mathrm{~nm}$ to calculate the specific activity $[10,11]$.

\section{Propanediol Dehydratase in vivo Assay}

The assay was carried out to evaluate the activities of three diol dehydratases on 1,2-propanediol. Three E. coli strains generated by transforming the wild type E. coli BW25113 with pYY93, pYY134, and pYY167 respectively were used for this purpose. Preinoculum from an overnight culture was added to $10 \mathrm{~mL}$ of $\mathrm{M} 9$ media $(1: 100 \mathrm{~V} / \mathrm{V})$ and grown at $37^{\circ} \mathrm{C}$. IPTG was added to the cultures to a final concentration of $0.1 \mathrm{mM}$ and 1,2-propanediol was added to the cultures as the substrate to a final concentration of $5 \mathrm{~g} / \mathrm{L}$ (65.7 $\mathrm{mM}$ ) after 4 hours. The cell cultures carrying pYY167 was grown anaerobically; while the cell cultures carrying pYY93 or pYY134 were grown micro-aerobically. Coenzyme-B12 (cobamamide) was also added to the cell cultures having pYY93 and pYY134 to a final concentration of $10 \mu \mathrm{M}$ after 4 hours. Samples were collected after 24 hours and analyzed for 1-propanol generation using HPLC-RID as described above. The enzyme activities were reflected by the formation of 1-propanol.

\section{Acknowledgements}

This work was supported by start-up funds from the Faculty of Engineering, The University of Georgia, Athens. We would also like to thank Dr. Mark Eiteman for his insight on enzyme assays and Sarah Lee for her technical assistance.

\section{Authors' contributions}

YY and RJ conceived the study. RJ performed the experiments under the guidance of $Y Y$. An equal contribution by $Y Y$ and RJ was made for literature review and drafting of the manuscript. Both authors read and approved the final manuscript.

\section{Competing interests}

The authors declare that they have no competing interests.

Received: 28 September 2011 Accepted: 10 November 2011 Published: 10 November 2011

\section{References}

1. Atsumi S, Hanai T, Liao JC: Engineering synthetic non fermentative pathways for production of branched-chain higher alcohols as biofuels. Nature 2008, 451:86-89. 
2. Atsumi S, Liao JC: Directed Evolution of Methanoccus jannaschii Citramalate Synthase for Biosynthesis of 1-Propanol and 1-Butanol by Escherichia coli. Applied and Environmental Microbiology 2008, 74:7802-7808.

3. Atsumi S, Liao JC: Metabolic engineering for advanced biofuels production from Escherichia coli. Current Opinion in Biotechnology 2008 19:414-419.

4. Connor MR, Atsumi S: Synthetic biology guides biofuel production. Journal of Biomedicine \& Biotechnology 2010.

5. Atsumi S, Cann AF, Connor MR, Shen CR, Smith KM, Brynildsen MP, Chou K, Hanai T, Liao JC: Metabolic engineering of Escherichia coli for 1butanol production. Metabolic Engineering 2008, 10:305-311.

6. Inokuma K, Liao JC, Okamoto M, Hanai T: Improvement of isopropanol production by metabolically engineered Escherichia coli using gas stripping. Journal of Bioscience and Bioengineering 2010, 110:696-701.

7. Shen CR, Liao JC: Metabolic engineering of Escherichia coli for 1-butanol and 1-propanol production via the keto-acid pathways. Metabolic Engineering 2008, 10:312-320.

8. International Programme on Chemical Safety. Environmental Health Criteria 102. 1-Propanol. [http://www.inchem.org/documents/ehc/ehc/ ehc102.htm].

9. Material Safety Data Sheet 1-Propanol. Caledon Laboratory chemicals [http://www.caledonlabs.com/upload/msds/8500-1e.pdf].

10. Altras NE, Cameron DC: Metabolic Engineering of a 1,2 Propanediol pathway in E. coli. Applied and Environmental Microbiology 1999, 65:1180-1185

11. Berrios-Rivera SJ, San KY, Bennett GN: The effect of carbon sources and lactate dehydrogenase deletion on 1,2-Propanediol production in Escherichia coli. Journal of Industrial Microbiology \& Biotechnology 2003, 30:34-40.

12. Altras NE, Cameron DC: Enhanced Production of (R) - 1, 2 Propanediol by Metabolically Engineered Escherichia coli. Biotechnology Progress 2000, 16:940-946.

13. Joon-Young J, Choi ES, Oh M-K: Enhanced Production of 1, 2 Propanediol by tpil Deletion in Saccharomyces cerevisiae. Journal of Microbiology and Biotechnology 2008, 18:1797-1802

14. Jeter RM: Cobalamin-dependent 1, 2 Propanediol utilization by Salmonella typhimurium. Journal of General Miicrobiology 1990, 136:887-896.

15. O' Brien JR, Raynaud C, Croux C, Girbal L, Soucaille P, Lanzilotta WN: Insight into the mechanismof the B12-independent glycerol dehydratase from Clostridium butyricum: preliminary biochemical and structural characterization. Biochemistry Journal 2004, 43:4635-4645

16. Roth JR, Lawrence JG, Bobik TA: Cobalamin (Coenzyme $B_{12}$ ): Synthesis and Biological Significance. Annual Review of Microbiology 1996, 50:137-181.

17. Luccio ED, Elling RA, Wilson DK: Identification of a novel NADH-specific aldo-keto reductase using sequence and structural homologies. Biochemistry Journal 2006, 400:105-114.

18. Honda S, Toraya T, Fukui S: In situ Reactivation of Glycerol-Inactivated Coenzyme $B_{12}$ Dependent Enzymes, Glycerol Dehydratase and Diol Dehydratase. Journal of Bacteriology 1980, 143:1458-1465.

19. Tobimatsu T, Azuma M, Matsubara H, Takatori H, Niida T, Nishimoto K, Satoh H, Hayashi R, Toraya T: Cloning, Sequencing, and High Level Expression of the Genes Encoding Adenosylcobalamin-dependent Glycerol Dehydrase of Klebsiella pneumoniae. The Journal of Biological Chemistry 1996, 271:22352-22357.

20. Tobimatsu T, Sakai T, Hashida Y, Mizoguchi N, Miyoshi S, Toraya T: Heterologous expression,purification, and properties of diol dehydratase, an adenosylcobalamin-dependent enzyme of Klebsiella oxytoca. Archieves of Biochemistry and Biophysics 1997, 347:132-140.

21. Raynaud C, Sarcabal P, Meynial-Salles I, Croux C, Soucaille P: Molecular characterization of the 1,3-Propanediol (1,3-PD) operon of Clostridium butyricum. Proceedings of the National Academy of Sciences of the United States of America 2003, 100:5010-5015.

22. Hopper DJ, Cooper RA: The purification and properties of Escherichia coli Methylglyoxal synthase. Biochemistry Journal 1972, 128:321-329.

23. Hopper DJ, Cooper RA: The regulation of Escherichia coli Methylglyoxal synthase; A new control site in glycolysis? Federation of European Biochemical Socities letters 1971, 13:213-216.

24. Ackerman RS, Cozzarelli NR, Epstein W: Accumulation of toxic concentrations of Methylglyoxal by wild-type Escherichia coli K-12. Journal of Bacteriology 1974, 119:357-352.
25. Stribling D, Perham RN: Purification and Characterization of Two Fructose Diphosphate Aldolases from Escherichia coli (Crookes' Strain). Biochemistry Journal 1973, 131:833-841.

26. Kruger NJ, Schaewen AV: The oxidative pentose phosphate pathway: structure and organisation. Current Opinion in Plant Biology 2003 6:236-246.

27. Jiang GR, Nikolova S, Clark DP: Regulation of the IdhA gene, encoding the fermentative lactate dehydrogenase of Escherichia coli. Microbiology 2001, 147:2437-2466.

28. Clugston SL, Barnard JF, Kinach R, Miedema D, Ruman R, Daub E, Honek JF: Overproduction and characterization of a dimeric non-zinc glyoxalase I from Escherichia coli: evidence for optimal activation by nickel ions. Biochemistry Journal 1998, 37(24):8754-63.

29. Lutz $\mathrm{R}$, Bujard $\mathrm{H}$ : Independent and tight regulation of transcriptional units in Escherichia coli via the LacR/O, the TetR/O and AraC/I1-I2 regulatory elements. Nucleic Acids Research 1997, 25:1203-1210.

30. Ausubel FM, Brent R, Kingston RE, Moore DD, Seidman JG, Smith JA, Struhl K: Current Protocols in Molecular Biology. New York, NY: John Wiley \& Sons; 1994.

31. Eiteman MA, Chastain MJ: Optimization of the ion-exchange analysis of organic acids from fermentation. Analytica Chimica Acta 1997, 338:69-75.

32. E. coli Genetic Resources at Yale CGSC, The Coli Genetic Stock Center. [http://cgsc.biology.yale.edu/].

\section{doi:10.1186/1475-2859-10-97}

Cite this article as: Jain and Yan: Dehydratase mediated 1-propanol production in metabolically engineered Escherichia coli. Microbial Cell Factories 2011 10:97.

\section{Submit your next manuscript to BioMed Central and take full advantage of:}

- Convenient online submission

- Thorough peer review

- No space constraints or color figure charges

- Immediate publication on acceptance

- Inclusion in PubMed, CAS, Scopus and Google Scholar

- Research which is freely available for redistribution

Submit your manuscript at www.biomedcentral.com/submit
C Biomed Central 